\title{
Three-defense Line Coordination Strategy of the Guizhou Power Grid with the New Security Situation
}

\author{
Wencheng Zheng, Tao Yu \\ South China University of Technology, Guangzhou 510640, Guangdong, China \\ Email: epwenchengzheng@hotmail.com
}

Received 2013

\begin{abstract}
In order to meet the requirements of Decree of the State Council of the People's Republic of China (No.599), this paper presents a three-defense line coordination strategy based on the Decree of the State Council (No.599). Taking the Guizhou power grid of $220 \mathrm{kV} \& 500 \mathrm{kV}$ as an example, the security and stability problem of the Guizhou power grid is analyzed. The strategy using three-defense line coordination for lowering the level of electricity safety accidents is researched. The analysis results show that the proposed coordination strategy is feasible, which can lower the level of electricity safety accidents under the same fault in same operation mode. Through studying the three-defense line of the Guizhou power grid, this paper presents a basic idea of the three-defense line coordination strategy based on the Decree of the State Council (No.599). The three-defense line coordination strategy provides reference for other provinces power grid.
\end{abstract}

Keywords: Security and Stability; Three-defense Line; the Guizhou Power Grid; Decree of the State Council (No.599)

\section{Introduction}

With the development of the smart grid, the power structure presents more and more complicated. The coordination problem of machine and network become increasingly prominent. The grid dynamic characteristics as well as the security and stability issues are increasingly complex. It also increases the grid stable operation of the control difficulty.

Along with the introduction of the Decree of the State Council (No.599), the security and stability of the power system is more and more attention. The security defense system of Power system must be established to ensure the system safe and stable operation. It mainly includes reasonable grid, reliable equipment, sound and effective three-defense line, efficient scheduling operation and management. Among all above, Setting three-defense line is a successful experience to run a security and stability power grid in China.

The provisions of China's electric power system to withstand large disturbance ability of the security and stability standards are divided into three levels [2-4]. In order to meet the requirements of the three standards of security and stability, a reasonable grid structure should be first built. The foundation of power system safe and stable operation needs a good system grid. Corresponding to the three standards, China has formed three-defense line concept. The construction of the grid is planning and configuration by three-defense line as well as the grid's scheduling operation and management. Over the years, China's power grid didn't appear a large area blackout. It benefited from the construction of three-defense line in accordance with the claim of the power system security and stability's guide [5-6].

The first line of defense is the most basic requirements of system safety performance. It generally doesn's not need to take measures. It achieves by the system automatically adjust device or the dispatching automation system's preventive controls. The accidents belong to the second line of defense happen with low probability, but it will harm system deeply. If effective measures do not be taken after the accident, it would expand the range of the system accident, even lead to the collapse of the system. So it needs to set emergency control device and take measures to guarantee the system's stability. The third line of defense is preventive measures that prevent the system appearing large area blackout and whole grid crash accident.

The research has been taken on the measures and control of grid security and stability of Guizhou main grid and the regional solitary power grid [7-8]. Base on the Guizhou Power Grid's configuration of three-defense line analysis in 2012, the paper analyses the adaption of the Guizhou Power Grid's three-defense line to the Decree of the State Council (No.599) and modifies the unsuited part. Then it proposes the basic idea of three-defense line coordination strategy under the Decree of the 
State Council (No.599).

\section{Guizhou Power Grid Security and Stability Analysis In 2012}

Using PSD-BPA and PSD-SSAP, the paper analysizes five typical operating modes of the Guizhou power grid in 2012. The five typical operating modes is summer maximum \& peak \& light load operation mode and winter peak \& light load operating mode.

\subsection{Small Signal Stability Analysis}

In three peak load operating mode, there are weakly damped oscillation mode in the grid. The main oscillation points are concentrated in the Tongren Area and Zunyi Area. It illustrates that these patches lack electrical damping. In order to improve area damping levels, the crucial generator sets such as Xiangziyan generating station in Tongren or Qianbei generating station in Zunyi may be considered to install PSS device or re-tuning the PSS parameters. Overall, in most cases, the small signal interference problem in Guizhou power grid isn't in a prominent place.

\subsection{Security and Stability Analysis of the $500 \mathrm{kV}$ Main Grid}

The prominent stability problems in Guizhou $500 \mathrm{kV}$ main grid are following.

(1) The double circuit line of $500 \mathrm{kV}$ from Anshun to Gaopo occurs short-circuited. It may lead the line of $500 \mathrm{kV}$ from Nayong Power Plant II to Gaopo overload.

(2) When $500 \mathrm{kV}$ Shibing transformer substation and Tongren transformer substation operates in open-loop, the double circuit line of $500 \mathrm{kV}$ from Shibing to Tongren occurs short-circuited. It will lead Tongren regional power grid and the main grid separate. Then the eastern part of Guizhou may appear frequency instability.

\subsection{Security and Stability Analysis of the $220 \mathrm{kV}$ Main Grid}

Guizhou $220 \mathrm{kV}$ grid centres in the each $500 \mathrm{kV}$ transformer substation. Each area runs independently. In 2012, there are sixteen $500 \mathrm{kV}$ transformer substations in Guizhou grid. That forms 16 regional grids. The prominent stability problems in Guizhou $220 \mathrm{kV}$ main grid are following.

(1) Siling power station send channel serious failure will lead transient instability problem in Tongren grid.

(2) Shatuo power station send channel serious failure will lead transient instability problem in Songtao grid.

\section{Three-defense Line Coordination Strategy Base on the Decree of the State Council (No.599) in Guizhou Power Grid}

\subsection{Accident Classification Base on the Decree of the State Council (No.599) in Guizhou Power Grid}

The Decree of the State Council (No.599) has published the ordinance of electrical safety incidents emergency disposal investigation and processing. The Ordinance is composed of six chapters. They are general principles, the report of the accident, emergency disposal, accident investigation and handling, liability, and annex. The most critical is divided accident level.

(1) The level of accidents is mainly determined by the proportion of the reducing load supply and the proportion of urban electricity customer outage.

(2) Grading standards of electrical safety accidents is a supplement on the basis of The Decree of the State Council (No.493). The core is defined four types of accidents. They are especially significant accident significant accident larger accident and generally accident.

Table 1 shows the accident corresponding level of Guizhou power grid. It can be drawn from the load distribution of all cities and counties in Guizhou Province

Table 1. Accident level of Guizhou power grid.

\begin{tabular}{|c|c|}
\hline Accident level & Judgment \\
\hline Especially Significant & 1 More than $40 \%$ load supply of the whole grid reduce \\
\hline Accident & 2 More than $60 \%$ load supply of the Guiyang City reduce \\
\hline & 1 Load supply reducing of the whole grid is among $16 \%$ to $40 \%$ \\
\hline Significant Accident & 2 Load supply reducing of Guiyang grid is among $40 \%$ to $60 \%$ \\
\hline & 3 More than $60 \%$ load supply of the Zunyi grid Liupanshui grid Anshun grid Tongren grid and Bijie grid reduce \\
\hline \multirow{3}{*}{ Larger Accident } & 2 Load supply reducing of Guiyang grid is among $20 \%$ to $40 \%$ \\
\hline & 3 Load supply reducing of Zunyi grid Liupanshui grid Anshun grid Tongren grid and Bijie grid is among $40 \%$ to $60 \%$ \\
\hline & 4 More than $60 \%$ load supply of the Kaili grid Duyun grid Xingyi grid Qingzhen grid and Fuquan grid reduce \\
\hline \multirow{4}{*}{ Generally Accident } & 1 Load supply reducing of the whole grid is among $6 \%$ to $12 \%$ \\
\hline & 2 Load supply reducing of Guiyang grid is among $10 \%$ to $20 \%$ \\
\hline & 3 Load supply reducing of Zunyi grid Liupanshui grid Anshun grid Tongren grid and Bijie grid is among $20 \%$ to $40 \%$ \\
\hline & 4 Load supply reducing of Kaili grid Duyun grid Xingyi grid Qingzhen grid and Fuquan grid is among $40 \%$ to $60 \%$ \\
\hline
\end{tabular}



of the State Council (No.599).

\subsection{The Coordination Strategy of the First Defense Line and Second Defense Line Research}

Power system operating status can be divided into: normal, alert, emergency, extreme urgency, collapse and recovery. Corresponding system run state changes, setting threedefense lines to ensure the safe and stable operation of power system encounters a variety of accidents. Figure 1 shows the relationship between the grid operating state conversion and three-defense line setting.

The coordination of the first defense line and second defense line refers to the system normal operation that preventive measures can't maintain effective system safety performance. Then the emergency control device take timely measures to maintain system stability. The coordination of the first defense line and second defense line is directly related to the system whether it can deal with low probability of occurrence of large fault or not. It is very important to the safe and stable operation of the system. Especially for system operation of the weak link, it should pay more attention. and the dividing standards of accident level in the Decree

The weak link of power system operation is the grid key transient stability section. Also it is the key object of the power grid stability analysis and monitoring. One of the important premises to guarantee the stability of the power grid is to control transmission section operating within transient stability limit.

In normal mode, there are three electromagnetic loop networks in Guizhou 500 - $220 \mathrm{kV}$ power grid. So Table 2 confirms seven sections that need to control the power flow.

Table 2. Section need to control the power flow.

\begin{tabular}{lc}
\hline \multicolumn{1}{c}{ Section } & Control Value (MW) \\
\hline Double circuit line from Xifeng to Guiyang & 2200 \\
Double circuit line from Yaxi to Nanbai & 480 \\
Double circuit line from Zunyi to Nanbai & 330 \\
$\begin{array}{l}\text { Double circuit line from Fuquan to Wenlang } \\
\text { Circuit I from Zhudong to Zhuling and }\end{array}$ & 280 \\
$\begin{array}{l}\text { Double circuit line from Qingyan to Zhudong } \\
\text { Line from Anshun to Xiayun and Double } \\
\text { circuit line from Anshun to Puding and }\end{array}$ & 500 \\
Line from Anshun to Yaopu & 400 \\
Double circuit line from Qinzhen to Zhanjie & 410 \\
\hline
\end{tabular}

Anti-disarrangement

Countermeasures

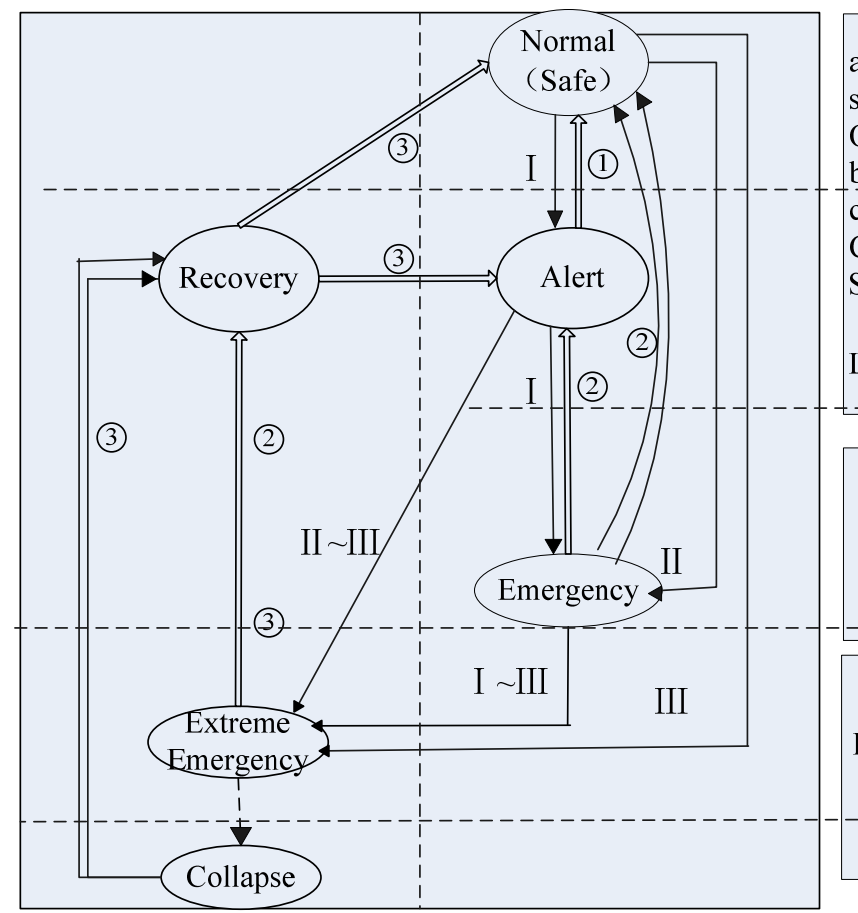

a)Reasonable grid

structure and

Operation mode

b)Grid fast protection

c)Prevention and

Control Device of

Security and stability

(The First Defense

Line)

Grid Emergency

Control Device

(The Second Defense Line)

a)Network Islanding

b)Voltage and

Frequency Emergency Control

(The Third Defense Line) \begin{tabular}{|l|}
\hline The first defense \\
line should take \\
protective measures \\
such as section \\
power flow control \\
to avoid Especially \\
significant accident \\
and significant \\
accident happen \\
\hline
\end{tabular}

The

Decree

of the

State

Council

(No.599

strategy of the

second defense line

and third defense

line should take

protective measures

to avoid larger

accident and

generally accident

happen
I - - Single Fault
II —-Single Serious Fault
III - - Multiple Serious Fault

(1) - - Preventive Control

(2) - Emergency Control

(3) - Regain Control

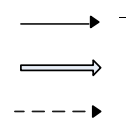

- - State Change Caused by Disturbances

- - State Change Caused by Control

- - State Change Must be avoided

Figure 1. The constraint of three-defense line coordination in The Decree of the State Council (No.599). 


\subsection{The Coordination Strategy of the Second Defense Line and Third Defense Line Research}

The second defense line needs the emergency control device that is configured in the system to take a cutting machine, load shedding, plan splitting and other measures to ensure the stability of the system. And it needs to take appropriate control measures in accordance with pre-established control strategy.

In normal operation mode, the Guizhou power grid needn't take stability control measures when the grid appears single fault. It maintains the stability of the power system operation and power supply through control power flow.

In the $500 \mathrm{kV}$ line $\mathrm{N}-1$ maintenance mode, a circuit line happens three-phase disconnect fault. If the influence of transmission limit is big, measures such as cutting machine, load shedding, cutting down DC transmission power should be taken to maintain the stability of the power system operation and the integrity of the main grid. Opposite, if the influence of transmission limit is small, it just needs to control power flow.

When the Guizhou power grid appears single serious fault, measures such as cutting machine, load shedding should be taken to maintain the stability of the power system operation and the integrity of the main grid. There are some weak links in the grid those happen single serious fault will cause the system instability. So the stability measures such as cutting machine, load shedding of the second defense line should be configured.

When the system appears multiple serious faults, it couldn't maintain the integrity of the whole grid. The system should be set measures such as system splitting, frequency and voltage emergency control to avoid system collapse and large area blackout. The protective devices of generating unit and line should avoid taking misoperation to prevent generating unit and line cascading trip when the system appears frequency oscillation. Guizhou power grid splitting point should be set based on the situation of the entire southern power grid system oscillation center. And it should guarantee the consistency of the splitting device action in the same section.

In order to restore stability of the system frequency after splitting, the system should configure enough cutting machine capacity and set the operating frequency and round reasonably. The emergency control of the frequency and the voltage mainly includes the low-frequency and low-voltage load shedding device [9,10]. Guizhou power grid should configure the low-frequency and lowvoltage load shedding device based on the grid situation of the section and the grid splitting.

\section{Three-defense Line Adaptive Analysis and Coordination Strategy Correction Base on the Decree of the State Council (No.599) in Guizhou Power Grid}

In 2012, the regional power grid of Xifeng, Guiyang, Jinzhou, Bijie, Anshun, Yaxi, Tongren and Songtao in Guizhou power grid appearrs all kinds of fault in each kind of operation mode. It will cause different effects after controlling of three-defense line. Table 3 shows that the most serious fault in each of these areas in Guizhou power grid is classed based on the Decree of the State Council (No.599).

Table 3. The electrical safety accidents grading of the Guizhou Power Grid in 2012.

\begin{tabular}{|c|c|c|c|c|c|}
\hline Area & $\begin{array}{l}\text { Operation } \\
\text { Mode }\end{array}$ & Fault & Stable Strategy & $\begin{array}{l}\text { The Proportion of } \\
\text { the Amount of } \\
\text { Load Shedding }\end{array}$ & $\begin{array}{l}\text { Accident } \\
\text { Level }\end{array}$ \\
\hline Guiyang & & $\begin{array}{l}\text { Guiyang substation one transformer is } \\
\text { overhaul and the other one is tripping }\end{array}$ & $\begin{array}{l}\text { 1.Shedding } 569 \mathrm{MW} \text { load } \\
\text { 2.Low-Frequency Load Shedding } \\
45 \mathrm{MW} \text { in first round }\end{array}$ & $14.41 \%$ & $\begin{array}{l}\text { Generally } \\
\text { Accident }\end{array}$ \\
\hline Bijie & $\begin{array}{l}\text { winter } \\
\text { peak load } \\
\text { operating }\end{array}$ & $\begin{array}{l}\text { Shexiang substation one transformer } \\
\text { is tripping }\end{array}$ & $\begin{array}{l}\text { 1. Shedding } 204 \mathrm{MW} \text { load } \\
\text { 2. Low-Frequency Load Shedding } \\
\text { 42MW in first round }\end{array}$ & $24.12 \%$ & $\begin{array}{l}\text { Generally } \\
\text { Accident }\end{array}$ \\
\hline Zunyi & mode & $\begin{array}{l}\text { Yaxi substation one transformer is } \\
\text { overhaul and the other one is tripping }\end{array}$ & Shedding $600 \mathrm{MW}$ load & $24.19 \%$ & $\begin{array}{l}\text { Generally } \\
\text { Accident }\end{array}$ \\
\hline \multirow{2}{*}{ Tongren } & & $\begin{array}{l}\text { Tongren substation one transformer is } \\
\text { overhaul and the other one is tripping }\end{array}$ & Shedding 233 MW load & $12.94 \%$ & --- \\
\hline & & $\begin{array}{l}\text { Songtao substation one transformer is } \\
\text { overhaul and the other one is tripping }\end{array}$ & Shedding 184 MW load & $10.22 \%$ & --- \\
\hline
\end{tabular}


(1) In winter peak load operating mode, Anshun substation operating in single transformer appears the fault of transformer tripping when the transformer transmission power is $630 \mathrm{MW}$. Then Anshun grid becomes an isolated network. The bus frequency deviation of the isolated network is shown in Figure 2(a). After shedding 620 MW load, the bus frequency deviation of the isolated network is shown in Figure 2(b). The total load of Anshun grid is 780 MW. The accident load accounts for $79.50 \%$ of the total load. It reaches significant accident according the Decree of the State Council (No. 599).

Through correcting the coordination strategy of threedefense line, it will not reach the accident level when the same fault occurred. The correct strategy is that when Anshun substation operating in single transformer, then the operation mode becomes electromagnetic loop network and controls the section power flow to meet $\mathrm{N}-1$ operation mode won't overload in electromagnetic loop network.

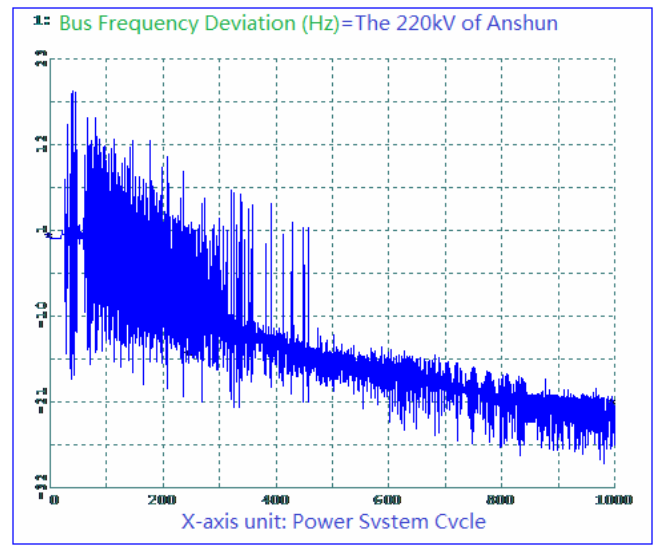

(a)
(2) In winter peak load operating mode, Xifeng substation operating in single transformer appears the fault of transformer tripping when the transformer transmission power is $972 \mathrm{MW}$. Then Xifeng grid becomes an isolated network. The bus frequency deviation of the isolated network is shown in Figure 3(a). After shedding 932 MW load, the bus frequency deviation of the isolated network is shown in Figure 3(b). The total load of Guiyang grid is $4261 \mathrm{MW}$. The accident load accounts for $21.87 \%$ of the total load. It reaches larger accident according the Decree of the State Council (No. 599).

Through correcting the coordination strategy of threedefense line, it will not reach the accident level when the same fault occurred. The correct strategy is that when Xifeng substation operating in single transformer, then the operation mode becomes electromagnetic loop network with Guiyang substation and controls the section power flow to meet N-1 operation mode won't overload in electromagnetic loop network.

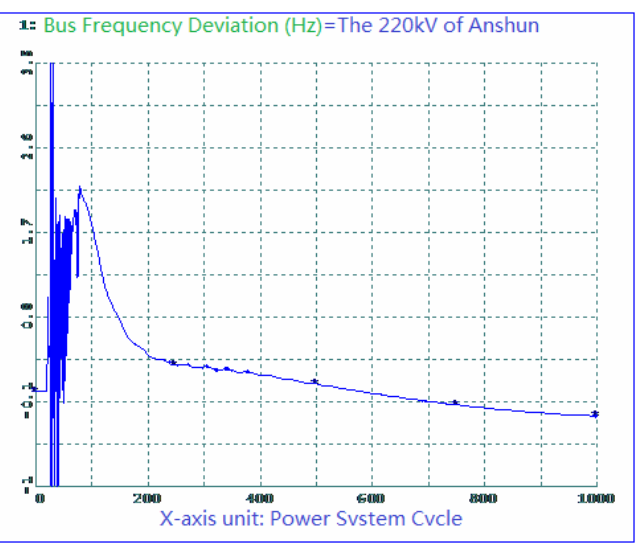

(b)

Figure 2. (a) The $220 \mathrm{kV}$ bus frequency deviation of Anshun; (b) The $220 \mathrm{kV}$ bus frequency deviation of Anshun after shedding load.

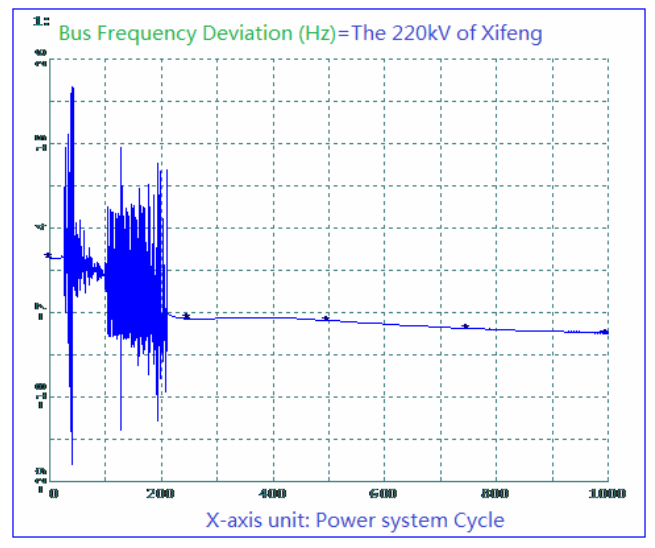

(a)

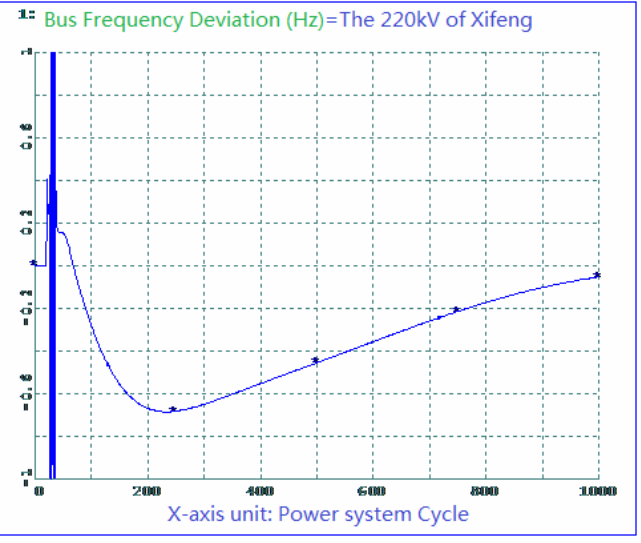

(b)

Figure 3. (a) The $220 \mathrm{kV}$ bus frequency deviation of Xifeng; (b) The $220 \mathrm{kV}$ bus frequency deviation of Xifeng after shedding load. 


\section{Conclusions}

Through the above analysis, it shows the configuration of three-defense line of the Guizhou grid in 2012 adapts to the Decree of the State Council (No.599). But there are some areas that don't set three-defense line or the existing coordination strategy can't reduce the accident level, operation mode should be adjusted to fix and improve. Then the high level accident could be avoided. So the configuration of three-defense line coordination strategy should take full consideration to the Decree of the State Council (No.599) that assesses accident level.

(1) The fault that will lead especially significant accident or significant accident should take protective measures such as the section power flow control in the first defense line to guarantee the significant accident or significant accident wouldn't happen.

(2) The fault that will lead larger accident or generally accident should take the coordination strategy of the second defense line and the third defense line. The self-healing of the system should be used as much as possible to reduce the capacity of the cutting machine and shedding load. Then it can reduce the accident level.

(3) In some maintenance mode, the measures such as load supply control and operation mode adjustment should be taken to prevent the accident level worse when the fault happens.

The result of the study were included in the planning of the safety and stability control device extension and rebuilt in the 2012 Guizhou grid. It played a certain role of reference and guidance in building the safety and stability control device.

\section{REFERENCES}

[1] State Council of the People's Republic of China, "The Emergency Disposal and Investigation Ordinance of Electrical Safety Fault," The Decree of the State Council, No. 599.

[2] People's Republic of China State Economic and Trade Commission, "Power System Security and Stability Guidelines,” China Electric Power Press, Beijing, 2001, p. 755.

[3] People's Republic of China State Economic and Trade Commission, "Technical Guide for Electric Power System Security and Stability Control,” DL/T723, 2000.

[4] “Y. S. Xue, "Space-time Cooperation Framework for Defending Blackouts: Part I From Isolated Defense Lines to Coordinated Defending," Automation of Electric Power System, Vol. 30, No. 1, 2006, pp. 8-16.

[5] Y. S. Xue, "Space-time Cooperation Framework for Defending Blackouts: Part III, Optimization and Coordination of Defense-line,"Automation of Electric Power System, 2006, Vol. 30, No. 3, pp.1-10.

[6] C. M. Zhou and B. Sun, "Study on Security and Stability Measures of the Isolated Grid Operation of the Guizhou Power Grid and Area Power Grids,” Power System Protection and Control, Vol. 36, No. 19, 2008, pp. 29-33.

[7] H. D. Sun, X. D. Wang and S. Y. Ma, "Measures to Improve System Security and Stability for Isolated Operation of Guizhou Main Power Grid and Its Regional Power Networks,” Power System Technology, 2008, Vol. 32, No. 17, pp. 35-40.

[8] "Power System Automatic Low-frequency Load Shedding Technology Provisions,”Chinese Ministry of Energy, 1991, pp. 428-1991.

[9] Y. S. Xue, X. C. Ren and Q. H. Wu, “A Review on Optimi Zation and Coordination of under Frequency Voltage Load Shedding," Automation of Electric Power System, Vol. 33, No. 9, 2009, pp. 100-107. 